Final Technical Report

May 1990

(Distributed August 1991)

\title{
Research on Thermophoretic and Inertial Aspects of Ash Particle Deposition on Heat Exchanger Surfaces in Coal-Fired Equipment
}

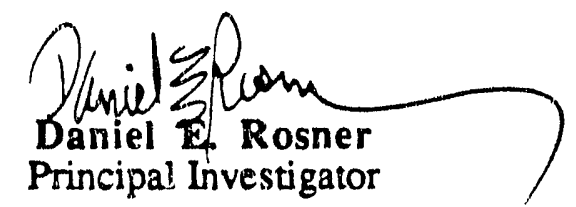

High Temperaure Chemical Reaction Engineering Laboratory

Yale University'. Department of Chemical Engineering

New Ha:en, CT 065:0-2159 U.S.A.

FAX (203)432-7232
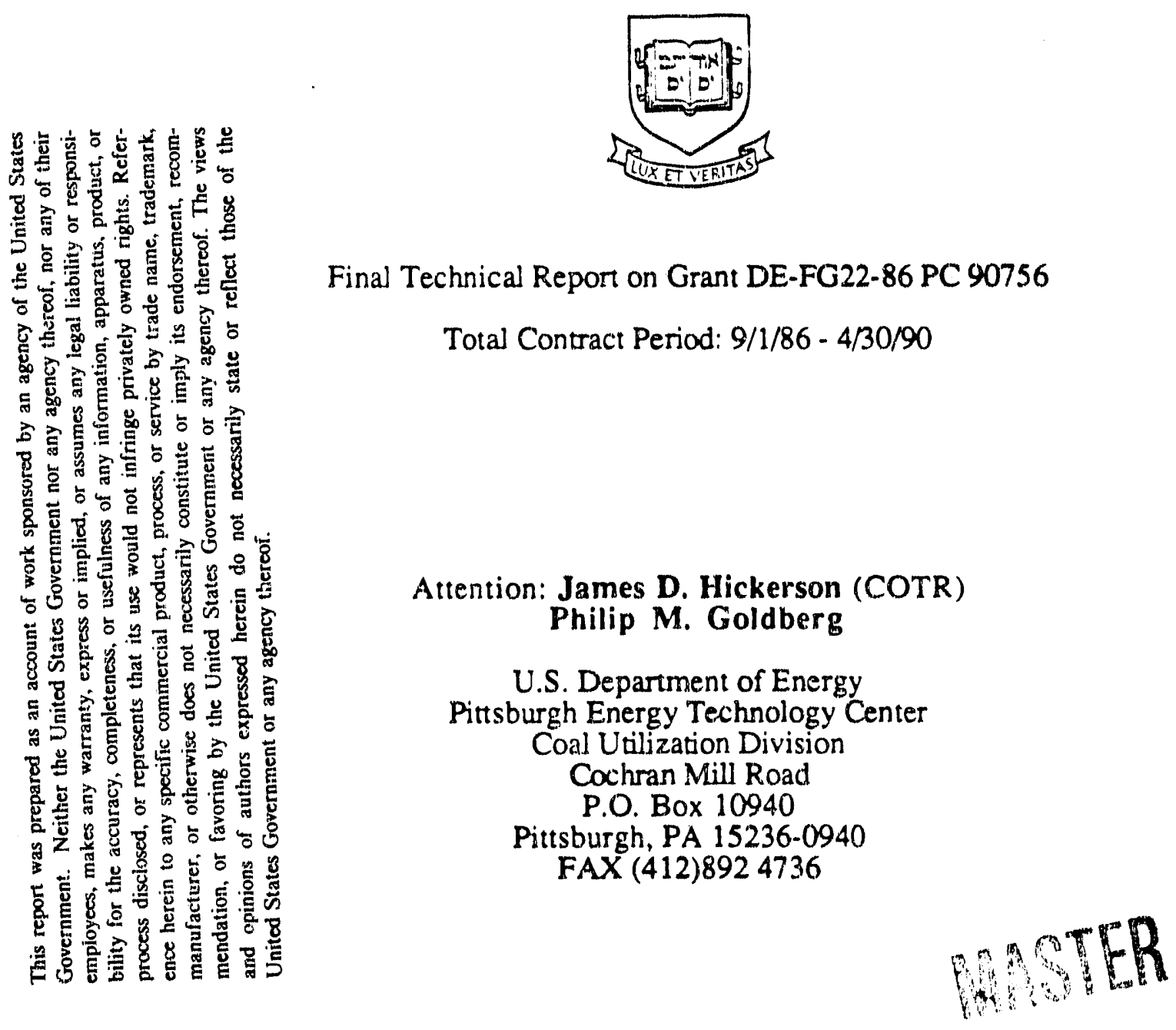
Final Report

Research on Thermophoretic and Inertial Aspects of Ash

Particle Deposition on Heat Exchanger Surfaces in Coal-Fired Equipment

\section{TABLE OF CONTENTS}

\section{INTRODLCTION}

1.1 Background

1.2 Objectives and Relation to DOE Mission

1.3 Project History and Scope

\section{RESEARCH ACCOMPLISHMENTS}

2.1 Experimental and Theoretical Studies of Particle Deposition in the Simultaneous Presence of Inertial and Thermophoretic Effects

2.2 Relations Between Deposit Microstructure, Effective Thermo-physical Properties and Particle Deposition Mechanism

2.3 Theory of Particle Deposition from 'Polydispersed' Aerosols

2.4 Counterflow Diffusion Flames for the Determination of Inorganic Particle Thermophoretic Diffusivities 2.5 Theory of Inertial Impaction on Aerodynamically Interacting
Targets

2.6 Role of Photophoresis in Combustors with High Radiative Heat Fluxes

3. ADMINISTRATIVE

3.1 Personnel

3.2 Acknowledgements--Cooperation with Industry

3.3 Dissemination of Information and Research Training

3.4 Known Applications of Yale-HTCRE Research Results

3.5 Follow-up Research: Opportunities and Plans

3.6 Concluding Remarks

4. REFERENCES

5. APPENDICES

5.1 Abstracts of Principal Publications (Areas 2.1-2.6) 


\subsection{Background}

\section{INTRODUCTION}

In September 1986 DOE.PETC initiated at the Yale HTCRE Laboratory a systematic experimental and theoretical research program directed toward providing engineers with the data, methods, and rational correlations needed to improve the generality and accuracy of prediction of inorganic particle deposition rates under typical coal combustion conditions (i.e., those leading to the importance of thermophoreticallyenhanced diffusion (submicron mode) and the inertially-enhanced "impaction" (supermicron mode), often in the presence of simultaneous alkali salt vapor condensation. After a brief statement of objectives (Section 1.2) we outline our principal experimental and theoretical results (Section 2, as documented in the references (Section 4). Section 3 gives relevant administrative information (personnel, total funding, acknowledgements, followon activities, known applications of this work,..)).

\subsection{Objectives and Relation to DOE Mission}

The overall goal of this research in the area of ash transport was to advance the capability of making reliable enginecring predictions of the dynamics and consequences of net deposit growth for surfaces exposed to the products of coal combustion. To accomplish this for a wide variety of combustor types, coal types, and operating conditions, this capability must be based on a quantitative understanding of each of the important mechanisms of mineral matter transport, as well as the nature of the interactions between these substances and the prevailing "fireside" surface of the deposit. This level of understanding and predictive capability could ultimately be translated into very significant cost reductions for coal-fired equipment design, development and operation.

\subsection{Project History and Scope}

Based, in part, on capabilities developed under previous deposition-related research programs supported in the Yale HTCRE Laburatory by AFOSR, NASA-Lewis Research Center and DOE-METC*, in the Fall of 1986 DOE-PETC initiated the present systematic three-yeart experimental and theoretical research program totalling $\$ 314,528$., directed toward providing engineers with the data, methods, and rational correlations needed to improve the generality and accuracy of prediction of inorganic particle deposition rates under typical coal combustion conditions (i.e., those leading to the importance of thermophoretically-enhanced diffusion (submicron mode) and the inertially-enhanced "impaction" (supermicron mode), often in the presence of simultaneous alkali salt vapor condensation.

Our emphasis in the present program: "Research on Thermophoretic and Inertial Aspects of Ash Paricle Deposition on Heat Exchanger Surfaces in Coal-Fired Equipment" was on developing and experimentally validating rational, theoretical methods of predicting the role of inertia and ash particle thermophoresis in determining net deposition rates. We also quantified how simultaneous vapor deposition (e.g., alkali sulfate) influences the sticking and erosion associated with impacting particles. Specifically(Section 2), as a result of this DOE-PETC supported program, we have developed:

+No-cost extensions brought the completion date to 30 April 1990.

\footnotetext{
* Our previous DOE-METC supported experiments have been confined to vapor and submicron particle systems in the absence of inertial phenomena (e.g. Rosner, 1989a). For an overview of convective mass transfer, sec the Pl's recent textbook (Rosner, 1986, 1988), especially Chapters 6, 8.
} 
- An improved understanding of the factors governing impacting particle capture and deposit erosion probabilities

- Ways of applying recent mass transfer theories (developed for idealized geometries) and available heat and momentum transfer data to develop prediction methods for important practical situations

- Necessary extensiors of available particle deposition rate theory and the phoretic properties of particles, (single spheres, aggregates).

- Useful, rational correlations to generalize the results of actual or numerical experiments and make them suitable for engineering design calculations

- The beginnings of an understanding of the fascinating interrelationship between deposition mechanism, deposit microstructure and deposit thermophysical properties (eg. thermal resistance, vapor diffusivity,...).

In developing tractable but realistic/rational procedures for predicting the evolution of wall deposits, we also intensified communications with more empirically oriented engineers/chemists with the necessary boiler fouling/slagging experience. Based on insights gained from the present program and its antecedents we are able to recommend economical 'subroutines' (compatible with practical requirements of global computer codes, recent deposition research results and cumulative empirical observations) to predict the evolution of wall deposits for, say, design studies of coal-fired furnaces and boilers .

\section{RESEARCH ACCOMPLISHMENTS}

Our principal accomplishments under Grant DE-FG22-86 PC 90756 (completed April 1990) can be logically divided into the following five sub-areas. Since our theoretical, computational and experimental techniques/methods and results are expounded in the cited publications (Section 4) readily available in the archival engineering literature* we indicate below only the essential features of our methods and results, and invite the interested reader to consult the indicated publications.*

\subsection{Experimental Studies of Particle Deposition in the Simultaneous Presence of Inertial and Thermophoretic Effects}

We have developed asymptotic methods to accourt for the simultaneous effects of inertia and thermophoresis on particle transport across laminar boundary layers (LBLs) with streamwise curvature. Predictions were compared with experimental data obtained using our seeded $\mathrm{C}_{3} \mathrm{H}_{8} / \mathrm{air}$ microjet burner set-up with curved platinum ribbon targets (see Fig. 2.1-1, and Konstandopoulos and Rosner,1989, Konstandopoulos, 1990)). This insulated burner has an internal volume of only $0.11 \mathrm{~L}$, is fabricated of castable ceramic, and operates at a pressure level of ca. $1.1 \mathrm{~atm}$. The combination of jet velocity $(\mathrm{ca} .73 \mathrm{~m} / \mathrm{s}$, and target radius of curvature $\left(0.6 \mathrm{~cm}\right.$.) lead to an effective body force of ca. $10^{4} \times($ Earth gravity)).The suspended particles were $\mathrm{MgO}(\mathrm{s})$ with a volume-mean diameter of $\mathrm{ca} .0 .8 \mu \mathrm{m}$.

\footnotetext{
* Reprints of any of these papers (and follow-on preprints) can be obtained by writing the PI ; abstracts of the principal publications cited here are included in Section 5.1
} 
The agreement of the data (obtained using an optical reflectivity technique previously developed/exploited at this laboratory)) with the abovementioned asymptotic theory (small Stk, large $\mathrm{Re}, \mathrm{Stk} \mathrm{Re}^{1 / 2}=\mathrm{O}(1)$ is seen to be gratifying and supports our contention that smallness of the conventionally defined particle Stokes number is no guarantee of small inertial effects in such cases. This is further demonstrated in the "map" shown in Fig.2.13. The consequences of (subcritical Stk) particle inertia on the predicted angular distribution of thermophoretic deposition for spheres and cylinders at high Reynolds numbers are displayed in Fig.2.1-4 (Konstandopoulos and Kosner,1990; Konstandopoulos, 1990). In addition, for completeness, we have also derived useful asymptotic $\left(\mathrm{Sc}>>1, \operatorname{Re}^{1 / 2}>>1\right.$, Stk $<1$ ) results for the effects of inertia on Brownian diffusion deposition rates on curved surfaces from isothermal LBL flows(Konstandopoulos, 1990).

\subsection{Relations Between Deposit Microstructure and Particle Deposition Mechanism}

Since it is clear that a knowledge of deposition rates in the absence of a theoretical understanding of the thermophysical properties of the resulting deposits will not allow designers to optimize future equipment, we have initiated studies of the systematic relations between deposit microstructure and particle deposition mechanism. Toward this end we recently completed a Monte-Carlo computer-simulation study of the subtle relations between particulate deposit microstructure and particle deposition mechanism (Tassopoulos, O'Brien and Rosner,1989). In two-dimensions the algorithm and "lattice" used for these "biased random walk" calculations is shown in Fig. 2.2-1 The resulting deposits reflect the relative roles of random- and directed-motions, but all such deposits are quite porous. We have initiated investigating alternative sticking and "restructuring" laws, and developed the capability to perform associated 3-dimensional off-lattice simulations to assess their influence on the resulting deposit microstructure. Such models result in much denser deposits (see, Figs.2.2-3,4) than those obtained using our earliest (relatively "unrestricted") active site sticking criterion (cf. Fig. 2.2-1). This class of Monte-Carlo simulation techniques opens the door to a number of relevari follow-on studies of the effective transport properties of these deposits (Tassopoulos, 1990), including capillary condensation of inorganic vapors within nonisothermal porous structures, and some of the effects of such liquid "bridges" on the capture of impacting particles (see, eg., Rosner and Nagarajan, 1987).

\subsection{Theory of Particle Deposition from 'Polydispersed' Aerosols}

We have developed theoretical methods to permit rapid prediction of total mass deposition rates from log-normally distributed aerosol populations of arbitrary spread $\sigma_{\mathrm{g}}$ (Rosner and Tassopoulos,1989), displaying results applicable to convective-diffusion of dense particles or agglomerates in the continuum or "free-molecule' regime. For example, Fig. 2.3-1, constructed for continuum diffusion of dense or fractal-like particles, shows the factor by which actual mass deposition ratres will differ from those calculated based on the (volume-)mean particle size in a population (of spread $\sigma_{\mathrm{g}}$ ). Our results (Rosner and Tassopoulos, 1989) also dramatically simplify the prediction of total mass deposition rates when one or several deposition mechanisms participate over important regions of the lognormal size spectrum (cf. Fig. 2.3-1). We have thus succeeded in generalizing a previous study (Rosner, 1989 ) which provided simple results for a 'single' mechanism (eg., convective-diffusion) and 'coagulation-aged' (self-preserving') distributions. This work also opens the door to prediction methods which allow for particle coagulation and vapor/particle interactions within boundary layers (for background research, see Park and Rosner, 1989, and Castillo and Rosner, 1988) as well as future studies of the simultaneous action of particlè-size-dependent wall deposition and coagulation. 


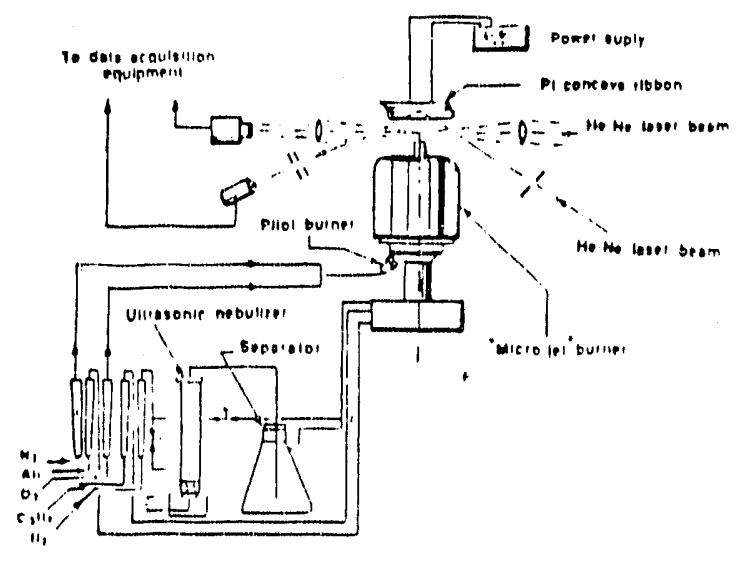

Figure 2.1 1.. Seeded microjel combustor apparatus (schematic) for optical reflectivity studies of inertially-modified thermophoretic deposition rates on solid target (platinum ribbon) with streamwise curvature (after Konstandopoulos and Rosner,1990)

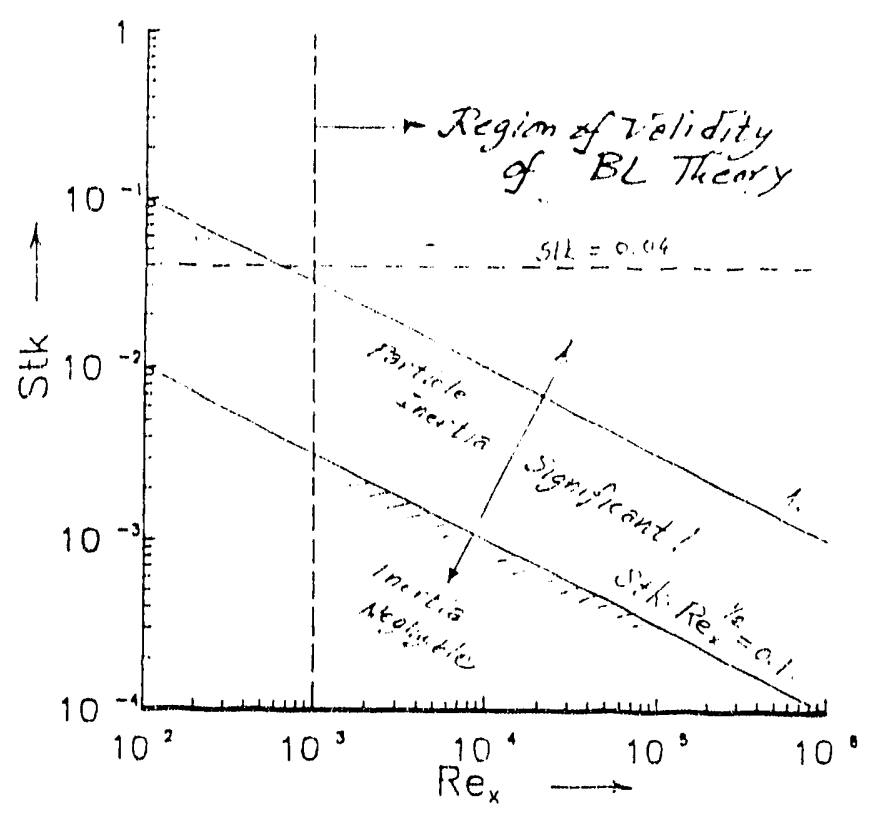

Figure 2.1-3. Domains on the map of particle Stokes number, Stk, versus Reynoids number $\mathrm{Re}$ showing the relevance of the product StkRe $\mathrm{e}^{1 / 2}$ in determining inertial effects in curved BL flows.(after Konstandopoulos and Rosner,1990)

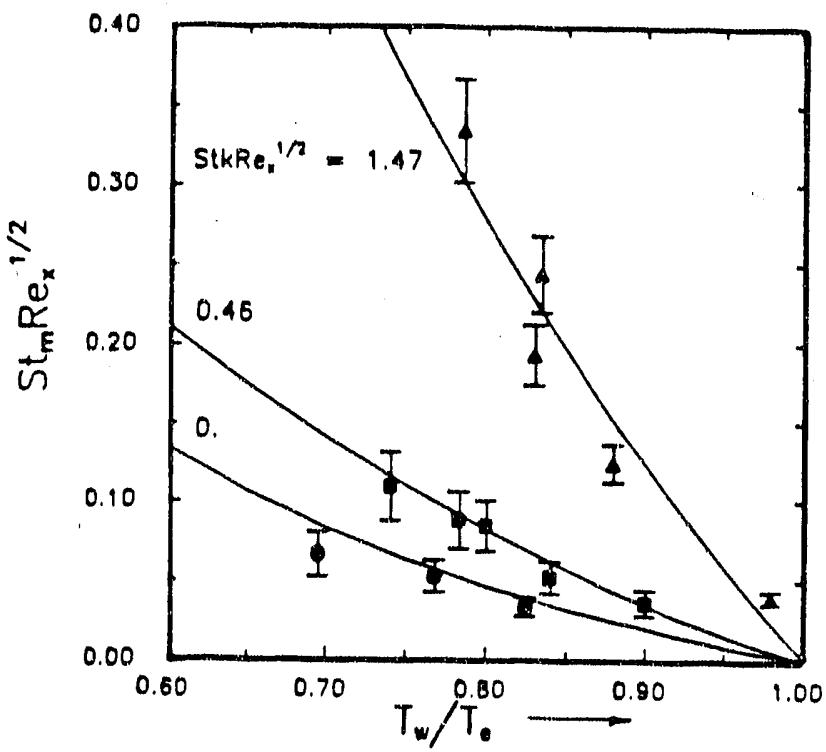

Figure 2.1-2. Experimental and theoretical particle deposition rate coefficient $S t_{m} R e_{x} / 12 v s$. temperature ratio $T_{w} / T_{e}$ and the relevant particle relaxation time parameter $S t k R e_{x}{ }^{l / 2}$ (after Konstandopoulos and Rosner,1990); Laminar BL flow, circular are solid target.

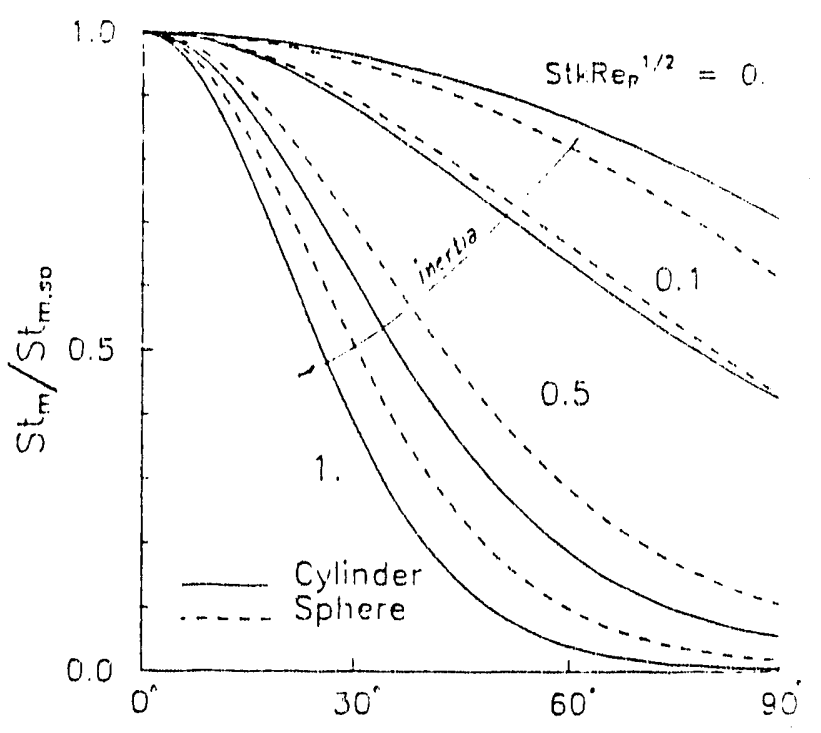

Figure 2.]-4. Predicted normalized distributions of thermophoretic deposition rate on cylinders and spheres in high Reynolds number crossflow; influence of the governing parameter $S i k R \varepsilon_{x}{ }^{1 / 2}$. (after Konstandopoulos,1990). 

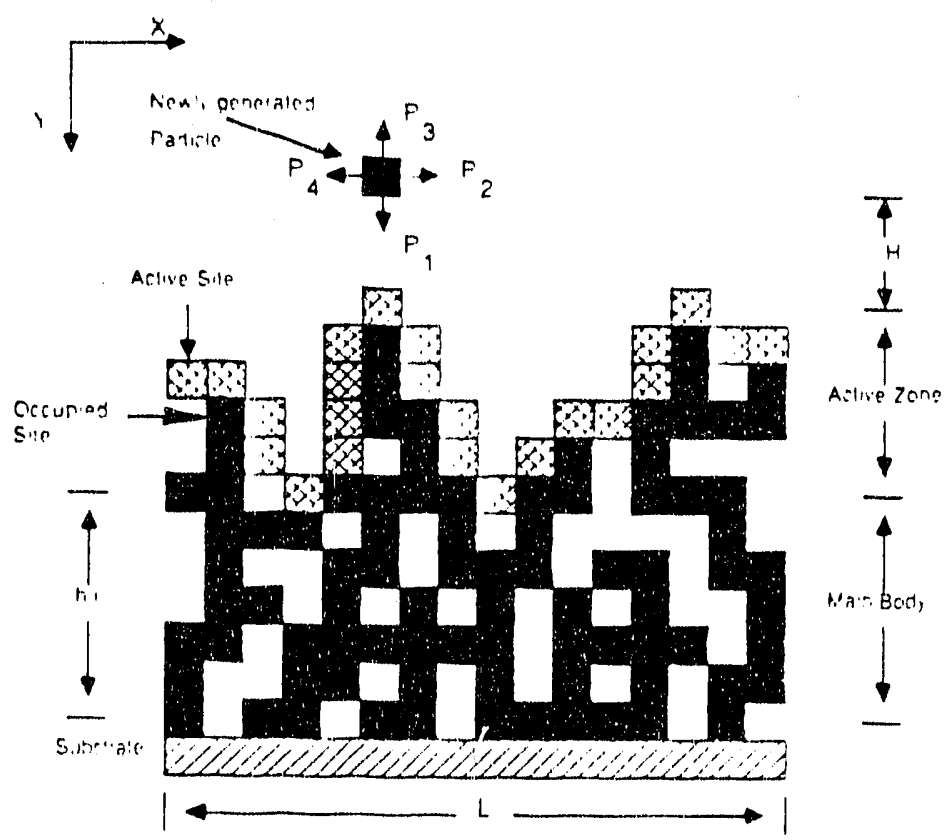

Figure 2.2.1 Monte-Carlo (biased random walk) algorithm used to "grow" two- (and three-) dimensional "on lattice" simulated microparticulate deposits(after Tassopoulos, O'Brien and Rosner, 1989)
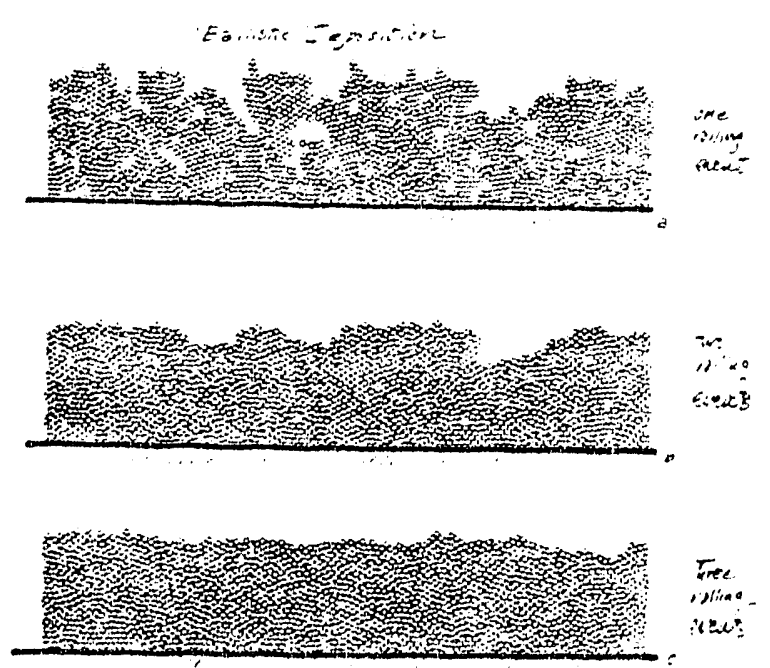

Figure 2.2-3 Predicted variation of deposit microstructure with post-arrival "restructuring" events...-in this case "rolling" to lower energy configurations.(after Tassopoulos, 1990)

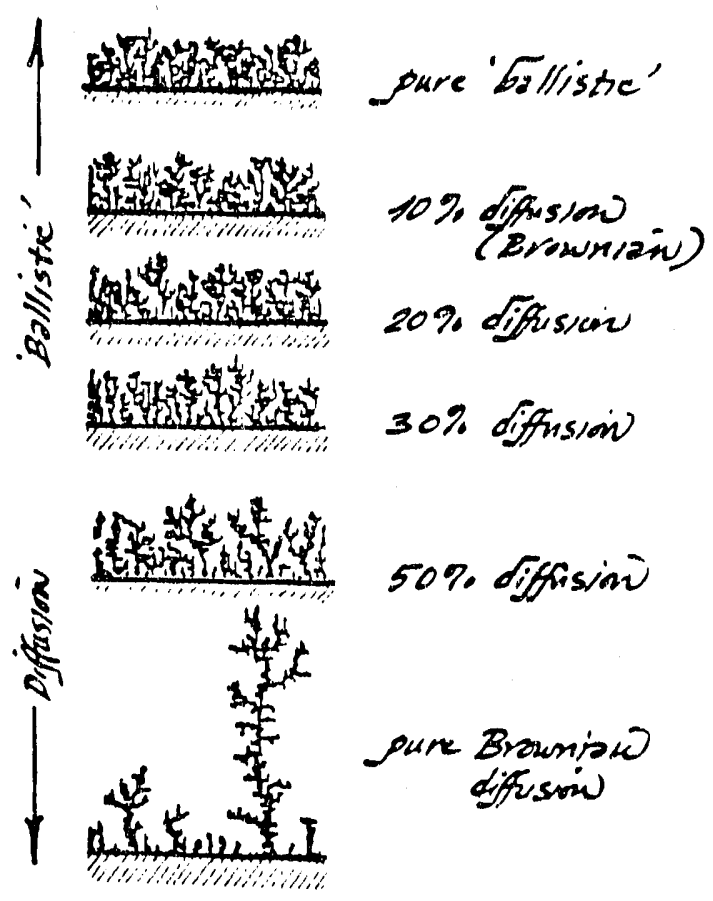

Figure 2.2.2 Predicted variation of deposit microstructure with deposition conditions.(after Tassopoulos, O'Brien and Rosner ,1989)
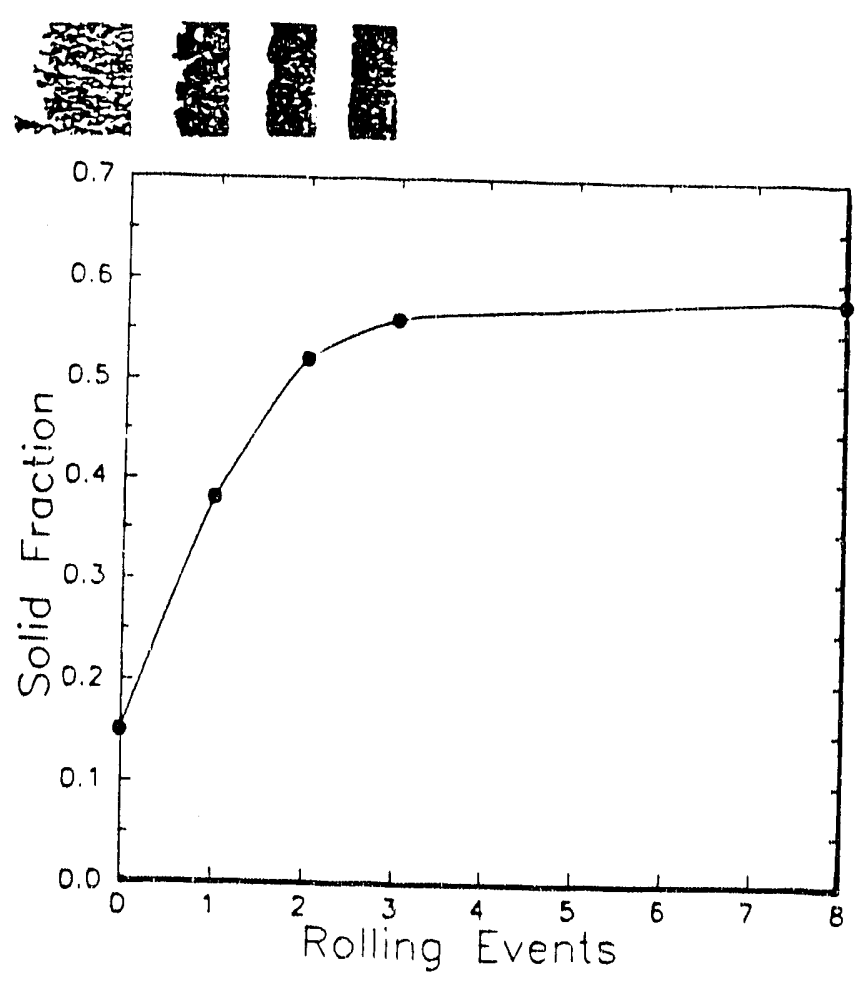

Figure 2.2-34 Predicted variation of particle deposit solid fraction with the number of postarrival "rolling events" (after Tassopoulos, 1990) 


\subsection{Counter-flow Laminar Diffusion Flames for the Determination of Inorganic Particle Thermophoretic Diffusivities \\ We have obtained experimental values of inorganic particle thermophoretic} diffusivities in high temperature combustion gas environments using a recently developed counterflow laminar diffusion flame (Fig.2.4-1) operated at low strain-rates (Gomez, et.al., 1988,1990). In the $\mathrm{CH}_{4} / \mathrm{O}_{2} / \mathrm{TiCl}_{4}$ experiments displayed in Fig. 2.4-2, (which includes the results of thermocouple temeperature measurements as well as particle axial velocities calculated from LDV observations of radial velocities) the thermophoretic diffusivity of submicron $\mathrm{TiO}_{2}$ particles in nitrogen-diluted counterflow gaseous diffusion flames was determined based on the existence of an easily observed ca. $1.5 \mathrm{~mm}$ thick thermophoretically-induced particle-free ('dark') zone and compared (ca. $10 \mathrm{pct}$. agreement) with the predictions of Waldmann's gas kinetic theory (Garcia-Ybarra and Rosner,1989). While further work will be required to complete these experiments, initial indications are that the orientation-averaged thermophoretic diffusivity of aggregated "soot" particles (inorganic or organic) is not very different from that of a single "primary" spherical particle. Replacing $\mathrm{N}_{2}$ by $\mathrm{He}$ dramatically increased the momentum diffusivity of the host gas, expanding the dark zone phenomenon despite the larger strain rates needed to stabilize such flames.

\subsection{Theory of Inertial Impaction on Aerodynamically Interacting Targets}

Inertial impaction of particles on an isolated circular cylinder target, especially at high $R e$, is now rather well understood. Classic studies in the aerosol literature have been extended to cover a larger range of parameters, and useful correlations for important quantities of interest have recently become available for routine engineering predictions (see, eg., Israel and Rosner,1983). However, except for several singular special cases, before our present study little was known about the "proximity" effects of adjacent collectors on the amount and distribution of inertial impaction on any particular collector in an array. Since such situations occur of ten in practice $e . g$. , in the entrance region of a heat exchanger tube bank, we have used the computationally efficient "method of images"(MOI) to construct potential flow fields around cylinder assemblies (see,eg. Fig. 2.5-1) and studied inerticil impaction on them, with the following objectives:

- To investigate how the number of collectors, $N_{c y l}$ and their spacing alter the collection characteristics of a single cylinder in such an array.

- To find appropriate ways to correlate the numerical results and provide an approximate, yet rational methodology for practical situations to circumivent, or at least dramatically reduce, the need for further detailed computations of the type we have performed.

Our results for a straight column of cylinders in cross-flow shown in Figure 2.5-2 (Konstandopoulos et al. ,1990) support the conjecture (cf. Israel and Rosner,1983) that an appropriately defined effective Stokes number, $S i k$ eff based on the dimensionless stagnation point fluid deceleration rate, $[d u / d x]_{0}$ :

$$
S t k_{\text {eff }} \equiv S t k \cdot\left[\frac{d u}{d x}\right]_{0}
$$

can adequately describe the collection efficiency of the central cylinder in the column. This description, based on our present calculations for columns containing from three to an infinite number of entrally spaced cylinders, seems to be valid for other quantities of interest as well (e.g., impact energies, particle concentration enrichment factors, etc.). Overall, it therefore now appears possible to estimate the collection efficiency of fluiddynamically interacting cylinders in cross-flow from a knowledge of the stagnation point gradient (given in Fig. 2.5-3, from Konstandopoulos et al. ,1990 as a function of number of cylinders and spacing) and the now well-known correlations for a single cylinder (see, eg., Israel and Rosner, 1983). 


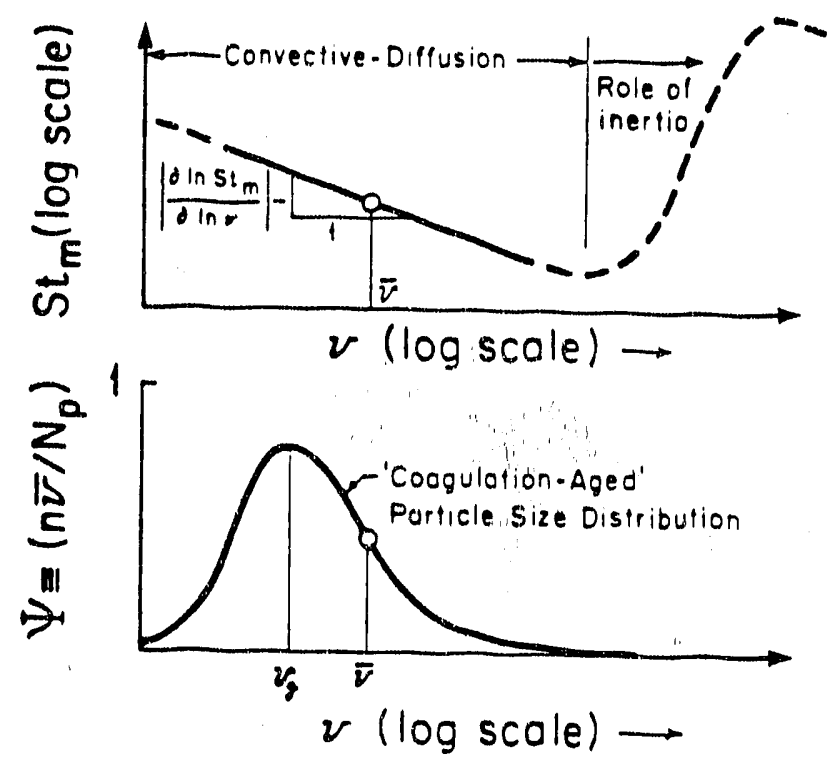

Figure 2.3-J Behavior of the dimensionless particle mass transfer coefficient, $S_{l_{m}}$, and dimensionless aerosol particle size distribution function, $\psi$, as a function of suspended particle volume, $v$ (log-log coordinates) in a particular case of particle morphologs/flow-field/target geometry (after Rosner, 1989)

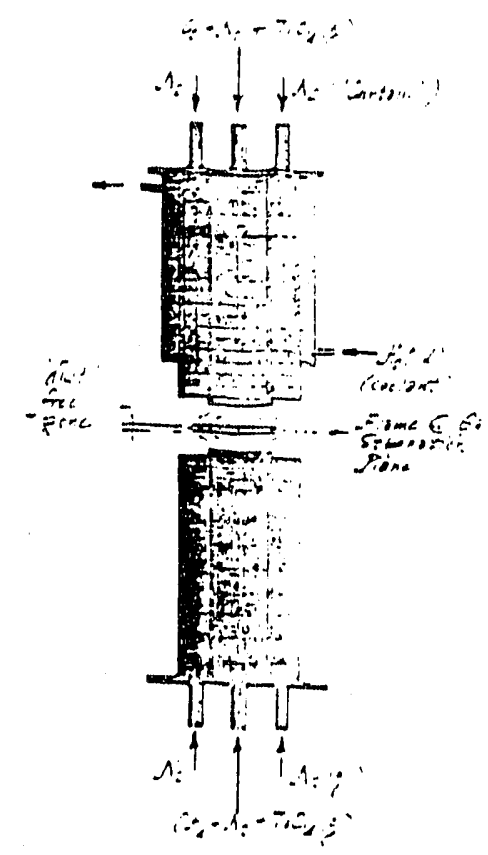

Figure 2.4-1 Seeded opposed-jet (counter-flow) laminar diffusion Rame burner configuration for the experimental determination of inorganic particle thermophoretic diffusivities (after Gomez and Rosner,1988,1990)

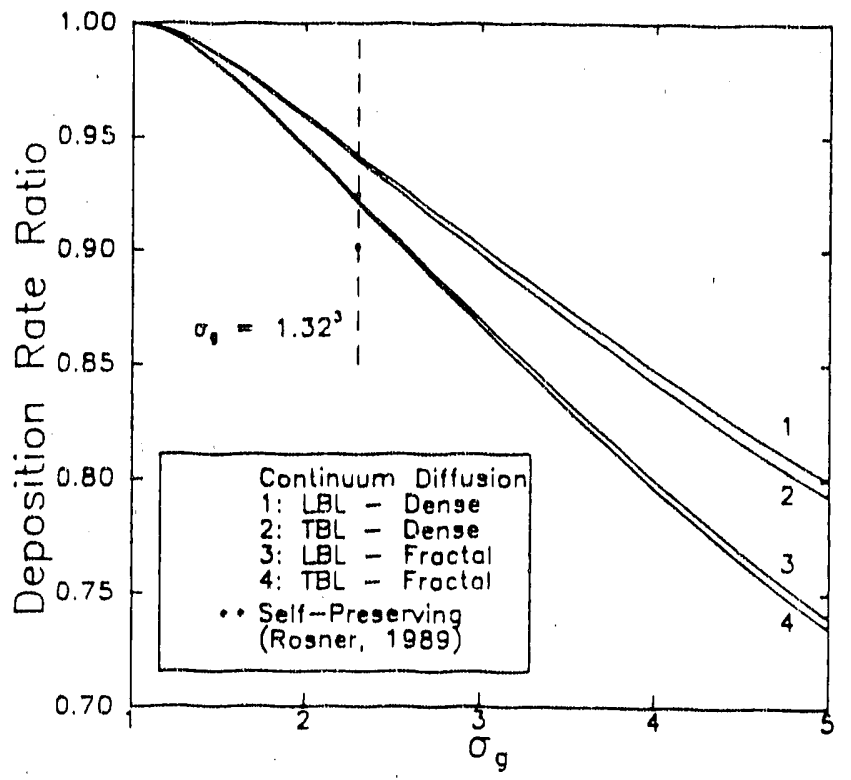

Figure 2.3-1 Predicted deposition rate ratio versus spread in aerosol population for Brownian (contiuum) diffusion of dense or "fractal" particles across laminar or turbulent boundary layers (after Rosner and Tassopoulos, 1989)

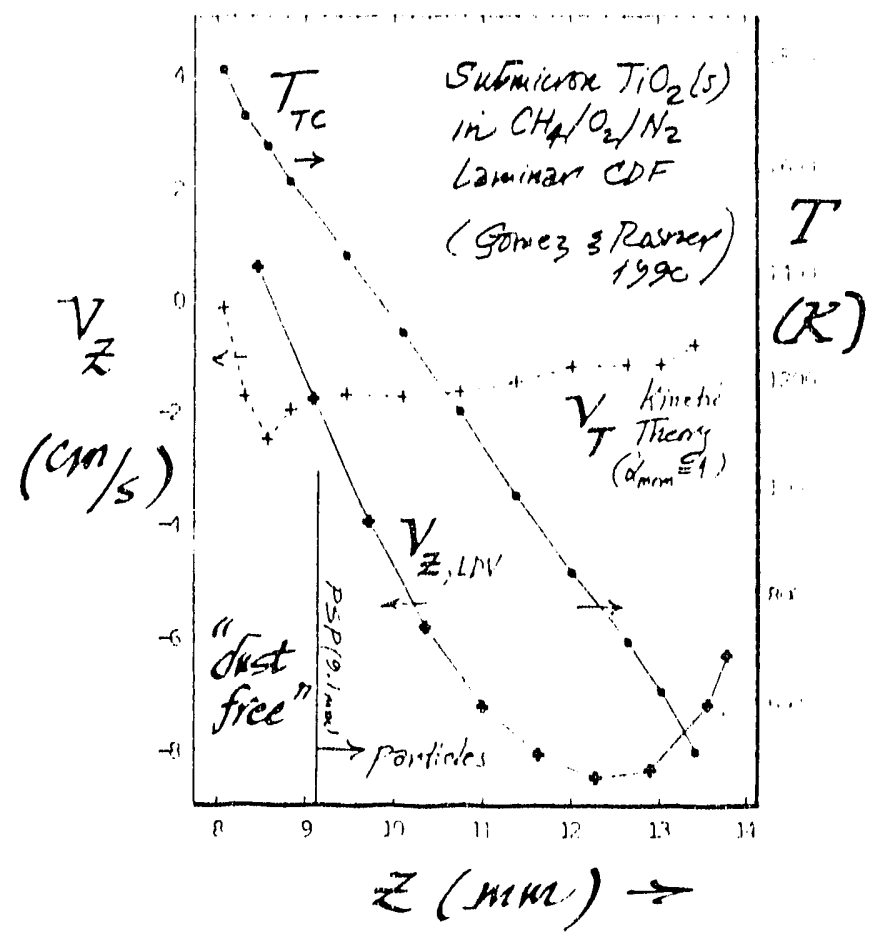

Figure 2.4-2 Measured gas temperatures and inferred particle velocities in seeded opposed-jet (counter-flow) laminar diffusion flame showing agreement between observerd position of "dust-free" zone and that predicted (kinetic theory) from singlesphere thermophoretic velocity (after Gomez and Rosner, 1988,1990) 


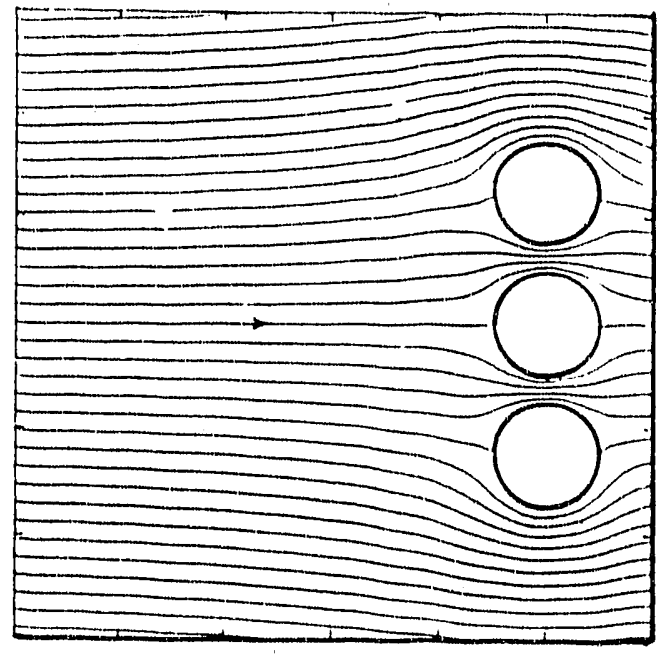

Figure 2.5-1 "Inviscid fluid flow past a column of adjacent (hy'drodynamically interacting) circular cylinders. Computed via the "method of images" (after Kostandopoulos, Labow'sky' and Rosner, 1990)

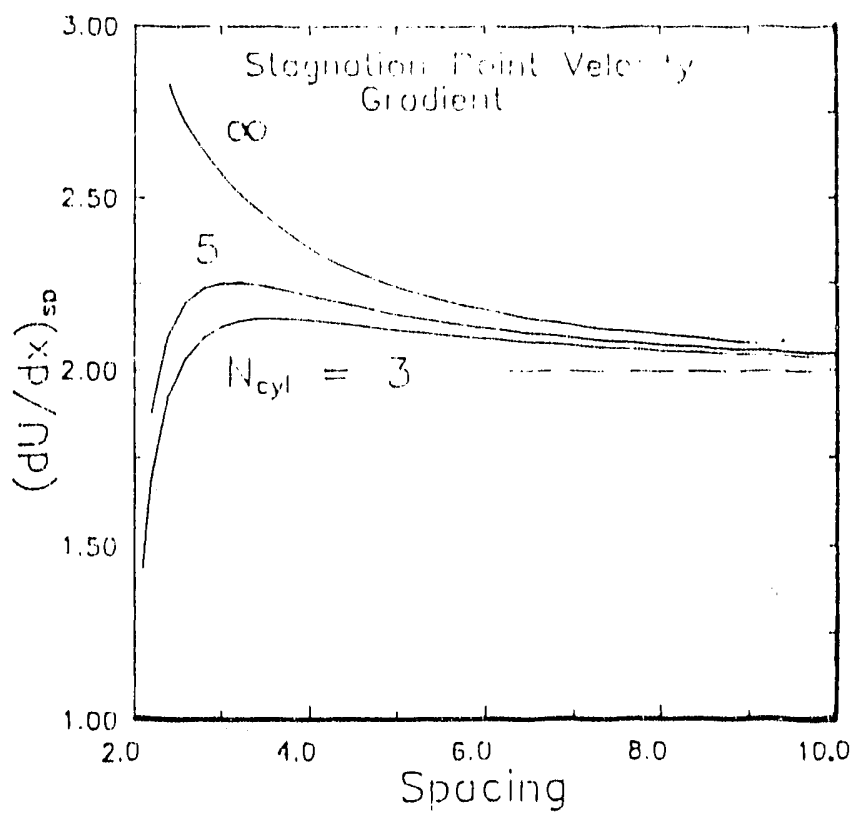

Figure 2.5.3 MOI-predicted dependence of the stagnation point(line) velocity gradient on the number and spacing of adjacent circular cylinders. (after Kostandopoulos, Labowsky and Rosner,1990)

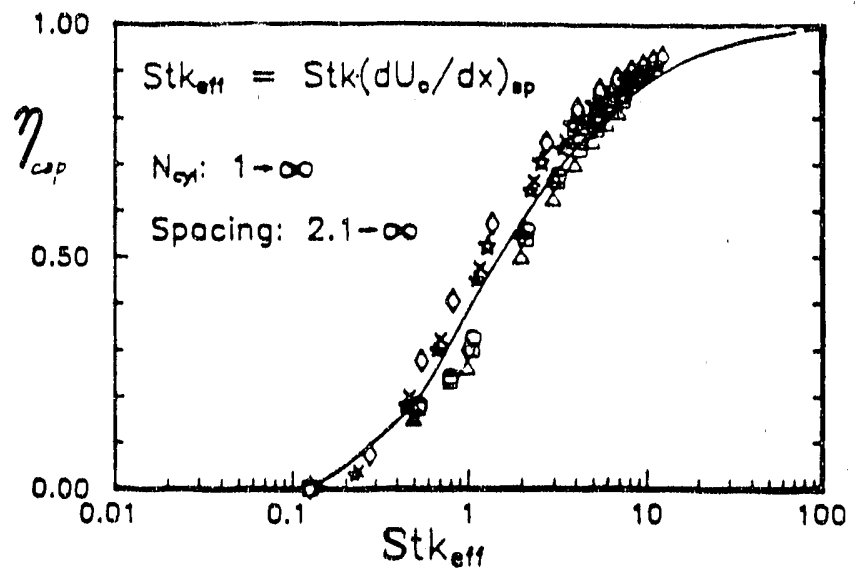

Figure 2.5-2 "Effective Stokes number" correlation of calculated inertial impaction fractions for high Reynolds number flow past a "column" of equidistant aerodynamically interfering circular cylinders in crossflow (after Konstandopoulos, et al. 1990)

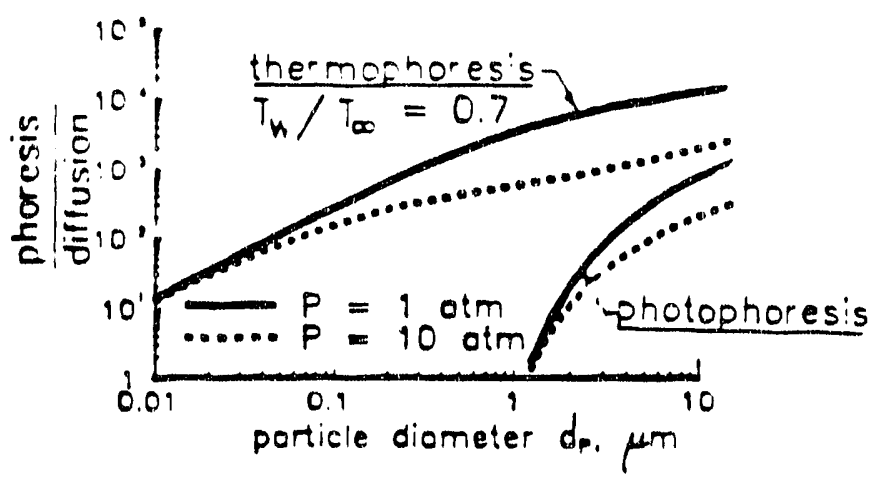

Figure 2.6.1 Relative importance of particle mass transpor by the mechanisms of Brownian diffusion (reference case), thermophoresis and photophoresis for equal radiative and Fourier energy flux ac ross laminar boundary layers.(Size dependence for absorbing spherical particles) (after Rosner et. al. 1990) 


\subsection{Role of Photophoresis in Combustors with High Radiative Heat Fluxes}

Particles can drift (exhibit 'phoresis') as a result of nonuniform photon-particle heating in a 'host' gas. Our analysis (Mackowski, 1988) of the photophoretic velocity of aerosol particles (which includes both the 'free-molecular' and the more important 'slipflow' regimes) shows that photophoresis can be a significant transport mechanism for micron-sized absorbing particles in high radiative transfer combustion environments (see, e.g., Fig 2.6-1 and Castillo, Mackowski and Rosner,1990). To demonstrate this we have predicted dimensionless transport coefficients (proportional to the ordinary Stanton number for mass transport; see, eg., Rosner,1986,1988) as a function of radiative/convective energy flux ratio and carbonaceous particle size for laminar boundary layer flow past a cooled solid surface. Large effects on the deposition rate of intermediate size particles $(e g$, between 1 and 10 micrometers) were found if the radiative flux is comparable to or exceeds the ordinary (Fourier) energy flux. For details the reader should consult Castillo, Mackowski and Rosner, 1990.

Despite the formidable complexities to be overcome in the design and operation of power plants utilizing a broad spectrum ash-bearing fuels these particular techniques and results are indicative of the potentially useful simplifications and generalizations which have emerged from our present fundamental DOE-PETC funded research studies of suspended particle deposition mechanisms and their connection to microparticulate deposit formation. It is hoped that this presentation and its supporting (cited) papers will facilitate the refinement and/or incorporation of some of the present ideas into design procedures of much greater generality and reliability, and help identify new directions where research results would have a significant impact on engineering practice.

\section{ADMINISTRATIVE}

This Final Report incorporates what would normally have been the last Quarterly Technical Report (\#12) for the period: 1 June 1989-31 August 1989, as well the two successive no-cost extension periods leading to the abovementioned 30 April 1990 program completion date. The following sections summarize some pertinent 'non-technical' facets of the abovementioned Yale HTCRE Lab/DOE-PETC research program:

\subsection{Personnel}

The present results (Sections 2,4 and 5) are due to the contributions of the personnel listed in Table 3.1-1, which also indicates the role of each researcher and the relevant time interval of the activity. It will be noted that, in addition to the results themselves, this program has simultaneously contributed to the research training of a number of students and fresh PhDs, who will now be in an excellent position to make future contributions to technologies oriented toward the efficient utilization of coal. 
Table 3.1-1 Summary of Research Participants on DOE-PETC Grant :

Research on Thermophoretic and Inertial Aspects of Ash Particle Deposition on Heat Exchanger Surfaces in Coal-Fired Equipment

\begin{tabular}{|c|c|c|c|}
\hline Name & Statusa & Date(s) & Principal Research Activityb \\
\hline Barghava, A. & UGRA(S) & 1988 & aerosol generator design/operat. \\
\hline Castillo,J. & PDRA-VS & 1988 & theory of alkali condens. in BLs \\
\hline Garcia-Ybarra,P. & PDRA-VS & $1988^{`}$ & kinetic theory of thermophoresis \\
\hline Goldmann,Y. & PDRA-VS & '86-'87 & microjet burner development \\
\hline Gomez,A. & PDRA-I & '86-'90 & meas. of particle transp. props. \\
\hline Konstandopoulos, A+. & GRA & '87.' 90 & thermophoresis/inertia coupling \\
\hline Labowsky,M. & VS & '86-' 90 & method of images calculations \\
\hline Liang, B. ${ }^{*}$ & GRA & 1986 & alkali scavenging in flames \\
\hline Mackowski,D.W. & PDRA & '88-'90 & photophoresis; aggregates \\
\hline Park, H.M*. & GRA & 87 & thermophoresis/inertia coupling \\
\hline Rosner, D.E. & PI & '86-'90 & program direction-dep.theory/ex \\
\hline Tassopoulos,M.+ & GRA & $87-90$ & microstructure/props. of deposit \\
\hline
\end{tabular}

a PDRA $=$ Post - doctoral Research Asst

$\mathrm{GRA}=$ Graduate Research Assistant

UGRA = Undergraduate Research Assistant

$\mathrm{I}=$ Instructor

$(S)=$ Summer

$V S=$ Visiting Scholar

PI = Principal Investigator

b See Section 4 for specific references cited in text (Section 2)

* Completed Yale PhD

+ PhD work expected to be complete by mid ' 91

\subsection{Acknowledgements-Cooperation with Industry}

The research summarized here was supported by DOE-PETC under Grant DEFG22-86-PC90756 (completed April 1990). The Yale HTCRE Laboratory has also been the beneficiary of continuing smaller grants from U.S. industrial corporations, including Babcox and Wilcox, Shell, Textron-Lycoming, DuPont, SCM-Chemicals, and Union Carbide, as well as the feedback and advice of principal scientists/engineers from each of these corporations and Combustion Engineering. We appreciate this level of collaboration, and expect that it will accelerate inevitable applications of our results in areas relevant to their technological objectives (see, also, Section 3.4, below).

\subsection{Dissemination of Information and Research Training}

Apart from the publications itemized in Section 4 and our verbal presentations (of progress) at regular DOE-ARTD Contractors Meetings, our results have also been presented at annual conferences of the following professional organizations:
AAAR
AIChE
ASME
Combustion Inst.
Fine Particle Society
Electrochemical Soc.

In addition, during the period: $9 / 1 / 86-4 / 30 / 90$, the PI has presented seminars at the following Universities:
Princeton
Johns Hopkins
Auckland
Cantebury
Queensland
Sydney

(the latter 4 during Prof. Rosner's Fall '88 leave from Yale University). We also hosted a Deposition Information Exchange Meeting for DOE Contractors at Yale University on 19,20 July 1988 , at which a summary of our work was presented. Another summary 
presentation is scheduled for later in 1990 in connection with the DOE Peer Review Assessment for this program.

This program was the focal point of the dissertation research of two graduate students (A.G.Konstandopoulos and M. Tassopoulos; cf.Table 3.1-1) expected to complete their degree requirements in 1991.

\subsection{Known Applications of Yale-HTCRE Lab Research Results}

It has been particularly gratifying to see direct applications of some of this DOEsupported particle and vapor mass transfer research in more applications-oriented fouling investigations reported in recent years. Indeed, the writer would appreciate it if further examples known to the reader can be brought to his attention.

The mosi explicit examples are provided in the work at MIT, and Sandia CRF, both groups having incorporated our rational correlation of inertial particie impaction (e.g. a cylinder in cross-flow) in terms of an effective Stokes number (Israel and Rosner,1983, Rosner, Gokoglu and Israel,1981, Rosner 1986). The goal of the first group was a more reliable fouling index based on improved models of the chemical composition and size distribution of fly ash particles, whereas the second group is assembling and beginning to test a practical method to predict the chemical composition of ash deposits under boiler conditions.

This PI was also pleased to recently leam (letter dated 1 August 1989) about applications of our DOE-supported research (on the correlation of inertial impaction. by cylinders in crossflow) by the National Engineering Laboratory (NEL) of Glasgow Scotland (Contact: Dr. Andrew Jenkins). NEL is apparently collaborating with Marchwood Labs-CEGB on developing fouling prediction methods applicable to waste-heat recovery systems in incinerators, as well as pulverized coal-fired boilers. These applications are somewhat similar to those reported by the Combustion Lab R\&D group at MIT (Walsh, Beer and Sarofim,1988)(see above).

In the area of alkali sulfate vapor deposition in chlorine-containing systems additional applications of our predictive methods (for "chemically frozen" and LTCE multicomponent laminar boundary layers) may be made by British Coal Corporation-Power Generation Branch (Dr. J. Duxbury, contact) in connection with their topping cycles which run gas iurbines on the products of fluidized bed coal combustors/gasifiers.

Explicit use of our studies of self-regulated "sticking"of incident impacting particles (Rosner and Nagaragan,1987) is being made in current work on impact separators and ceramic heat exchangers for coal-fired turbine systems. Other potential applications arise in conection with "candle filters" used to remove fines (sorbent particles,...) upstream of the turbines. A useful summary of work in these interrelated areas (Solar Turbines, Textron Defense Systems, Hague International,...) will be presented at the forthcoming Engineering Foundation Conference (Scheduled at Palm Coast, FL for March 1991):

Inorganic Transformations and Ash Deposition During Combustion. We plan to present a review of the principal results of this DOE Program at this conference

Clearly, fruitful opportunities for the application of our recent deposition research now exist in many of the programs currenuly supported by DOE-PETC and METC.

\subsection{Follow-on Research: Opportunities and Plans}

The time is now ripe for timely extensions of the work described in Section 2, as well as further applications of our recent/current studies of ash deposition mechanisms, particle capture/erosion, and deposition mechanism-deposit microstructure-property interrelations. In addition to proposed activities directly related to those described in 
Section 2 (to be submitted to DOE-PETC in Fall '90), we plan to respond to future (January 1991?) Coal Research at US Universities Proposal Requests to expand the scope of this program. We also look forward to intensifying our cooperation with applicationsoriented corporations active in this general field.

\subsection{Concluding Remarks}

The results of the present DOE-PETC program (Section 2) are indicative of the potentially useful simplifications and generalizations emerging from our current fundamental research studies of suspended particle deposition mechanisms and their connection to microparticulate deposit formation. Our experimental and theoretical investigations will continue in each of the specific areas summarized in Section 2, as well as in new areas needing investigation, with the goal of ultimately providing engineering designers with better "tools" for making rational assessments of ash deposition phenomena in future, high-performance coal-fired equipment. It is hoped that this Final Technical Report will accelerate this process by calling attention to the results of this particular program.

\section{PUBLICATIONS*}

Castillo, J.L., Mackowski, D., and Rosner, D.E., "Photophoretic Contribution to the Transport of Absorbing Particles Across Combustion Gas Boundary Layers", ACSDiv. Fuel Chemistry ; Presented at the Symposium on Ash Deposition, 197th Annual ACS Mtg., Dallas TX, April 9-14, 1989 Progress in Energy and Combustion Science 16,253-260 (1990)*

Castillo,J.L., Garcia-Ybarra,P.L., and Rosner,D.E.,"Morphological Stability of a Thermophoretically Growing Deposit", 7th Int. Symposium on Physicochemical Hydrodynamics, MIT (1988) (in press, J.Crystal Growth ,1990)*

Castillo,J.L., and Rosner, D.E. "Non-equilibrium Theory of Surface Deposition from Particle-Laden, Dilute Condensible Vapor-Containing Streams, Allowing for Particle Thermophoresis and Vapor Scavenging within the Laminar Boundary Layer",Int. J. Multi-phase Flow 14,(1), 99-120, (1988)

Castillo,J.L., and Rosner, D.E. "Theory of Surface Deposition from a Unary Dilute Vapor-containing Stream Allowing for Condensation within the Laminar Boundary Layer" Chemical Engineering Science,44,(4) $925-937$ (1989)*

Castillo,J.L., and Rosner, D.E. "Equilibrium Theory of Surface Deposition from ParticleLaden Dilute, Saturated Vapor-containing Laminar Boundary Layer" Chemical Engineering Science,44,(4) 939-956(1989)*

Castillo,J.L., and Rosner, D.E. "Theory of Surface Deposition from a Binary Dilute Vapor-containing Stream Allowing for Equilibrium Condensation within the Laminar Boundary Layer" Int. J. Multiphase Flow 15 (1) 97-118 (1989)*

Garcia-Ybarra, P. and Rosner, D.E.,"Thermophoretic Properties of Non-spherical Particles and Large Molecules", AlChE J.,35,(1),139-147, (1989)*

Fernandez de la Mora, J. and Rosner, D.E., "Effects of Inertia on the Diffusional Deposition of Small Particles to Spheres and Cylinders at Low Reynolds Numbers",J. Fluid Mechanics, 125, 379-395 (1982)

\footnotetext{
- Asterisk denotes publications supponted in full, or a significant par, by the present DOE-PETC Grant DEFG22-86 PC 90756. Section 5.1 gives abstracts of the principal publications in each of Areas 2.1-2.6 (Section 2). Several studies, initiated under the present grant, will be published as part of our follow-on research activities (see Section 3.4)
} 
Gokoglu, S.A., and Rosner, D.E.,"Correlation of Thermophoretically-Modified Small Particle Diffusional Deposition Rates in Forced Convection Systems with Variable Properties, Transpiration Cooling and/or Viscous Dissipation", Int. J.Heat Mass Transfer 27, 639-645 (1984)

Gokoglu S.A., and Rosner, D.E.,"Thermophoretically Enhanced Mass Transport Rates to Solid and Transpiration-Cooled Walls Across Turbulent (Law-of-the-Wall) Boundary Layers", IEC Fundamentals 24,(2), 208-214,(1985)

Gomez, A., Smooke, M.D. and Rosner, D.E., "Application of Counterflow Diffusion Flames to the Determination of Particle Thermophoretic Diffusivities", Presented at the 22nd Int Combustion Symp (Poster session) August 15-19, 1988, Seattle, WA.

Konstandopoulos, A.G, Yale Univ. PhD Dissertation (in preparation,1990)*

Konstandopoulos, A.G., Goldman, Y. and Rosner, D.E., "Experimental Studies of Inorganic Particle-Laden High Temperature/Velocity Jet Impingement at Collecting Surfaces; Sticking and Deposit Erosion in the Simultaneous Presence of Condensing Alkali Sulfate Vapors"; Presented at the 18 th Annual Meeting of the Fine Particle Society, Symposium on Multiphase Flow, Boston, MA 8/3-7/1987*

Konstandopoulos, A.G., and Rosner, D.E., "Experimental Studies of the Combined Effects of Particle Inertia and Thermophoresis on Deposition Rates Across Laminar Combustion Gas Boundary Layers" (Ms.in preparation, 1990)*

Konstandopoulos, A.G., and Rosner, D.E., "Theoretical Studies of the Combined Effects of Particle Inertia and Thermophoresis on Deposition Rates Across Laminar Combustion Gas Boundary Layers" (Ms.in preparation, 1990)*

Konstandopoulos, A. G., Labowsky, M. and Rosner, D. E. (1991) "Inertial Deposition of Particles from Potential Flows past Cylinder Assemblies", Accepted for presentation at AAAR 1990 Annual Meeting, paper 5E.6, June 18-22, 1990, Philadelphia, PA. (being prepared for 1991 submission to J. Aerosol Sci.)*.

Liang, B, Gomez,A., J. Castillo and Rosner D.E."Experimental Studies of Nucleation Phenomena within Thermal Boundary Layers - Influence on Chemical Vapor Deposition Rate Processes", Chem. Engrg Communications 85,113-133,(1989)*

Mackowski, D., "Photophoresis of Aerosol Particles in the Free-Molecular and Slip-Flow Regimes", I.J.H.M.T. ,32,(5) 843-854 (1989a)*

Mackowski,D.W.,"Phoretic Behavior of Asymmetric Particles in Thermal Non-equilibrium with the Gas; Part I: Two-Sphere Aggregates" J. Colloid Interface Sci (in press, 1990)*

Park, H.M. and Rosner, D.E..,"Combined Inertial and Thermophoretic Effects on Particle Deposition Rates in Highly Loaded Dusty-Gas Systems, Chemical Engineering Science, 44 (10) 2233-2244 (1989)*

Park, H.M. and Rosner,D.E.,"Thermophoretically Induced Phase Separation in Highly Mass-Loaded 'Dusty' Gas Mixtures", HTCRE Lab Publication No.162, Sepiember 1988*

Park,H.M., and Rosner, D.E., "Boundary Layer Coagulation Effects on the Size Distribution of Thermophoretically Deposited Particles", Chemical Engineering Science,44,(10) 2225-2231 (1989)*

Rosner, D.E., Nagarajan, R. Kori, M.and Gokoglu, S.A.,"Maximum Effect of Vapor Phase Chemical Reactions on CVD-Rates and Deposition Onset Conditions in the Absence of Interfacial Chemical Kinetic Barriers", Proc. 10th Int. Conf. on CVD, The Electrochem. Soc. (G.W. Cullen, ed.) Vol. 87-8, 61-80 (1987)*

\footnotetext{
*Asterisk denotes publications supported in full, or a significant part by the present DOE-PETC Grant DEFG22-86 PC 90756. Section 5.1 gives abstracts of the principal publications in each of Areas 2.1-2.6 (Section 2). Several studies, initiated under the present grant, will be published as part of our follow-on research activities (see Section 3.4)
} 
Rosner, D.E., "Mass Transfer Across Combustion Gas Thermal Boundary Layers Power Production and Materials Processing Implications", in Heat Transfer in Fire and Combustion Systems, HTD 45, ASME, NY-NY, 3-8 (1985)

Rosner, D.E., Transport Processes in Chemically Reacting Flow Systems, Butterworths, Stoneham, MA (1986); Third Printing, 1990*

Rosner, D.E., "Total Mass Deposition Rates from 'Polydispersed' Aerosols"; AlChE J. 35,(1) 164-167,(1989)*

Rosner, D.E., "Experimental and Theoretical Studies of Inorganic Matter Deposition from Combustion Gases",Invited paper for the Benjamin G. Levich Memorial Volume of Physicochemical Hydrodynamics, 10, Nos. 5,6, 663-674 (1988)*

Rosner,D.E. and Liang, B.,"Experimental Studies of Deposition Rates in the Presence of Alkali Sulfate Vapor Scavenging by Submicron Particliss in Combustion Gas Boundary Layers",Chem. Engrg. Commun. 64, 27-46,(1988)*

Rosner, D.E., and Nagarajan, R., "Toward a Mechanistic Theory of Deposit Growth from Ash-Laden Flowing Combustion Gases: Self-Regulated Sticking of Impacting Particles and Deposit Erosion in the Presence of Vapor 'Glue'", in AlChE Symposium Series 83, No.257, Heat Transfer-Pittsburgh 1987 (R.W. Lyczkowski, ed.) 289-296 $(1987)^{*}$

Rosner,D.E. and Tassopoulos,M, "Deposition Rates From Polydispersed Particle Populations of Arbitrary Spread", AJChE J. 35,(9), 1497-1508 (1989)*

Rosner,D.E., Mackowski, D.W.,Tassopoulos,M., Castillo, J., and Garcia-Ybarra,P., "Effects of Heat Transfer on the Dynamics and Transport of Small Particles in Gases", Poster Scheduled for Presentation at: Ninth International Heat Transfer Conference (AIChE,ASME,ANS) 19-24 August, 1990, Jerusalem, Israel.*

Seshadri,K and Rosner, D.E.,"Optical Methods and Results of Dew-Point and Deposition Rate Measurements in Salt/Ash-Containing Combustion Gases-- $\mathrm{B}_{2} \mathrm{O}_{3}(l)$ Deposition Rates by Interference Methods and Comparison With Theory", AIChE J.,30,(2), 187 196,(1984)

Tassopoulos, M. Yale Univ. PhD Dissertation (in preparation, 1990)*

Tassopoulos, M., O'Brien, J.A., and Rosner, D.E., "Simulation of Microstructure / Mechanism Relationships in Particle Deposition,"AIChE J. 35,(6),967-980,(1989)

Tassopoulos,M., O'Brien, J.A., and Rosner, D.E. "Simulation of Deposits Generated by the Capture of Particles that Follow Deterministic Trajectories"; presented at the 1989 AIChE Annual Meeting, 6.10 November 1989, San Francisco, CA.* Asterisk denotes publications supported in full, or a significant part, by the present DOE-PETC Grant.DE-
FG22-86 PC 90756 Section 5.1 gives abstracts of the principal publications in each of Areas $2.1-2.6$
(Section 2). Several studies, initiated under the present grant, will be published as part of our follow-on
research activities (see Section 3.4)

\section{APPENDICES (attached)}

\subsection{Abstracts of Principal Publications (Areas 2.1-2.6)}




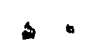
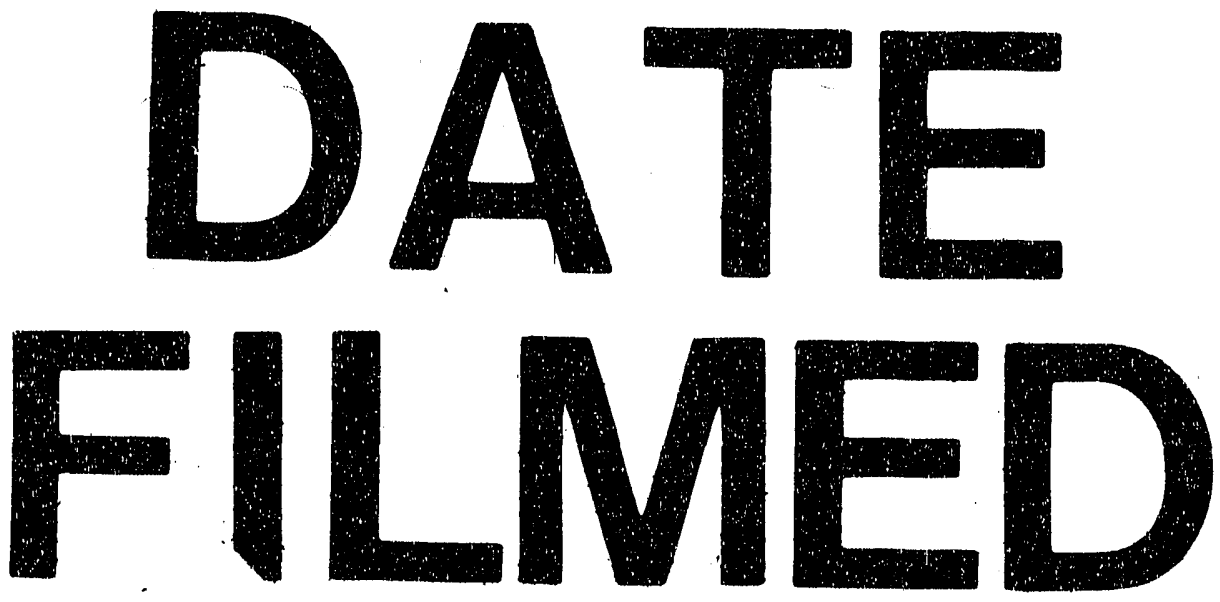

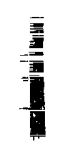

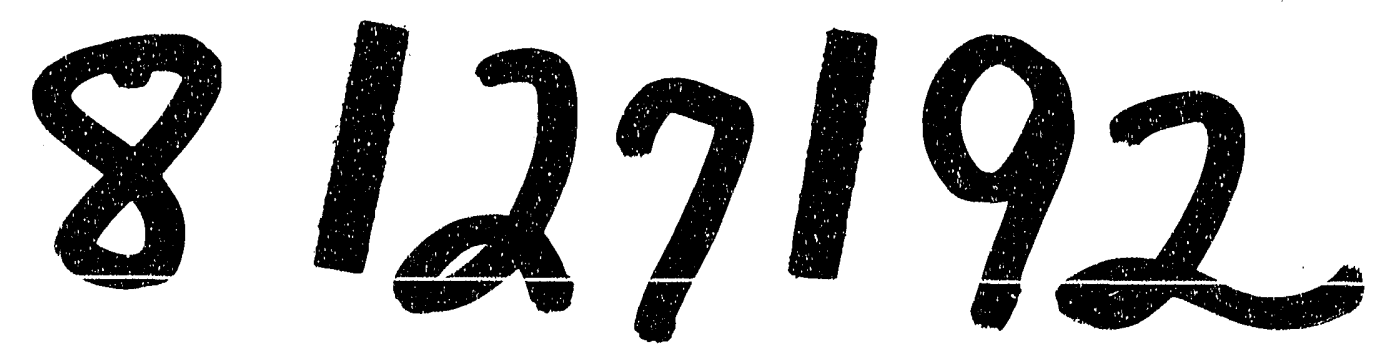


1 